\title{
Delphic Maxims based Applied Philosophy for Business and Governance Management
}

\author{
Evangelos Markopoulos ${ }^{1}$, Hannu Vanharanta ${ }^{2}$ \\ ${ }^{1}$ University of Vaasa (UVA), School of Technology, Department of Production, \\ FI 65101, Vaasa, Finland \\ epm@empross.com \\ ${ }^{2}$ Tampere University of Technology (TUT), Industrial Management, \\ Pohjoisranta 11 A, P.O. Box 300, FI-28101 Pori, Finland \\ hannu.vanharanta@tut.fi
}

\begin{abstract}
Knowledge analysis and representation is significant towards defining situations before being executed by activities. Knowledge engineering precedes knowledge management and knowledge utilizations needs knowledge creation. On the race for capturing and mastering knowledge emphasis is given on the development on intelligent methods and tools to understand the human mind, but not the human itself. To tackle complexity it is necessary to seek knowledge in non trivial sources via root cause analysis models on philosophical wisdom that usually has the answers. As problems become more complex over the time, synergies of knowledge disciplines are critical and necessary. This paper presents a triadic categorization approach, based on classes, taxonomies and ontologies, of the Delphic Maxims, and their analysis by cognitive models in an attempt to reveal their contribution to the modern business and governance management through the essence of the Hellenic contribution the global economy, civilization and humanity.
\end{abstract}

Keywords: Applied Philosophy · Knowledge Management · Business Management Governance $\cdot$ Strategy $\cdot$ Leadership.

\section{$1 \quad$ Introduction}

Knowledge is the key word in research, development, achievement, progress, prosperity, success and anything that can be associated with creativity and wisdom. Knowledge drives all progressive activities, initiatives, projects, processes, and anything that can be considered a step ahead in professional and personal development [1]. Furthermore, true knowledge is power, and power is freedom, in contrast to ignorance, which can be seen as slavery. Those who have knowledge are really free, not only to reach truth but also to create through truth. Human beings cannot possess anything that they do not perceive, interpret and understand. As the circles of mind grows, so does the circumference of the darkness around it, verifying Socrates' words "This one thing I know, that I know nothing" [2]. On the other hand, having knowledge alone is not enough. Knowledge has a nature of a tool, and tools can only be effective in the hands of the person who holds them properly and wisely. Knowledge can contribute creatively but also destructively, unless developed within ethical, and not only legitimate, principles [3]. Despite the fact that knowledge is certainly a magic recipe, it has always been extremely difficult to define what knowledge is and what it is not. Once such a distinction can be achieved, at least to a degree, then anything related to knowledge can be significantly improved, starting from the knowledge elicitation process, all the way to knowledge utilization and capitalization. The distance between knowledge creation and knowledge utilization is vast, as there are many steps that interfere in this interpretation and transformation of knowledge into something that can indeed be capitalized successfully, effectively, and rewardingly [4]. The need for the development of more affective classification models and methods in order to apply them in 
understanding the various civilizations of humanity towards true knowledge generation is paramount. It is vital for the progressive continuation of the modern society and economy to learn from the knowledge of the past and utilize it today to progress with it to the future.

\section{The Delphic Maxims}

An important source of knowledge that contributed significantly to the development of humanity is found in the Delphic Maxims [5] of the Hellenic civilization.

The Delphic maxims are aphorisms said to have been given by the god Apollo's Oracle at Delphi [6]. The maxims are 147 commandments composed in the 6th century B.C. that include much of the wisdom and the teachings of ancient Hellenes in laconic sentences, written in the area of the Delphic Oracle. Located at Delphi, on the slopes of Mount Parnassus, home of Pegasus, the Oracle was built at the place considered the Navel of the Earth, the center of the world. The maxims themselves are also known as "The Commandments of the Seven," and are said to have been written by the seven sages of Ancient Greece at Delphi, where they were inscribed. The seven sages were Solon of Athens, Chilon of Sparta, Thales of Miletus, Bias of Priene, Cleobulus of Lindos, Pittacus of Mitylene, and Periander of Corinth. The 147 maxims with no more than four words each, carrying deep philosophical meanings, making their classification quite complex depending on the interpretation given.

\section{Analysis Approach}

The universal meaning of the Delphic Maxims can be approached thorough multidisciplinary practices and techniques. Ontologies can be used to define the space in which each maxim meaning moves and changes per instance of interpretation and usage. Taxonomies can be used to define the categorization of the maxims, and classes can be used to define the relationships between the elements of each class. Interpreting the Delphic Maxims as applied philosophy of business management and administration could be a significant contribution to the global economy and society. The maxims can be analyzed by their interpretation, application, contribution and have impact in decision making, strategy, leadership, human resources management, goals setting, organizational commitment, ethos and overall entrepreneurial and corporate philosophy. Such an analysis can develop new management frameworks affected by concepts and values for optimal organizational performance based on the best utilization of the capability and maturity of the human resources [7]. Organizations suffer, not because they cannot solve their problems, but because they cannot identify them. Lack of problem identification is due to lack of corporate communication, which in turn is due to lack of corporate culture, which is due to a lack of corporate philosophy on values based on the basic principles of humanity and civilization.

\section{Ontologies, Taxonomies and Classes}

Ontology (Fig. 1) [8], derives from the Hellenic 'on' (őv), genitive 'ontos' (óv being," and 'logia' ( $\lambda_{0} \gamma(\alpha)$ ): science, study, theory. Taxonomy (Fig. 2) [9] derives from the

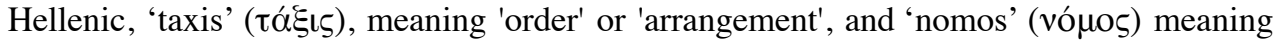
'law' or 'science'. The breakdown of the Hellenic meanings are: Ontology $=$ science of being, Taxonomy = arrangement science. 


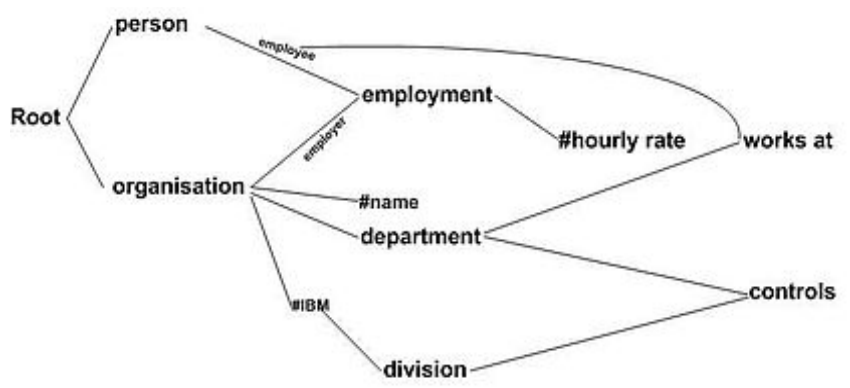

Fig. 1. An Ontology Tree Diagram

Therefore, taxonomy is the simple hierarchical arrangement of entities with a parent-child kind of relationship [10], [11]. An ontology, is a more complex variation of a taxonomy as it also defines spaces for taxonomies. The purpose of a taxonomy is knowledge classification, while ontology goes beyond into "knowledge representation". Classes are taxonomical ranks, indicating interrelationships (including inheritance, aggregation, and association), operations, and attributes [12].

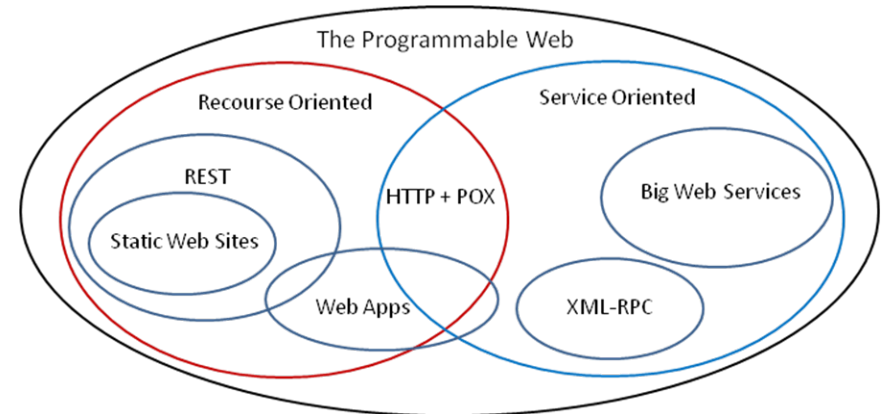

Fig. 2. A Taxonomy Diagram

The representation of classes can be in a tree or relationship arrangement, based on the properties/attributes of the classes or the behavior a particular class is allowed to perform. An example of the Ontology-Taxonomy-Class relationship could be given with the following example. "To be or not to be?" would be an ontological question. according to taxonomy "you're one of the humans", and based on the classes "you are a Hellene". Therefore, the ontology is the description, the taxonomy is the classification, and the class is the rank or category within the taxonomy of an ontology. Viewing this triadic classification relationship from a distance, a holistic knowledge representation is achieved not only in understanding large sets of information, but also exploring its interpretation through various paths and relationships. After all, knowledge is obtained by observation.

\section{Delphic Maxims Ontologies}

The wisdom of the Delphic Maxims is quite magnificent; therefore the classification of such wisdom can only be approached using ontologies to define the knowledge spaces. Many maxims can ignite different classification knowledge paths in various directions that can be interpreted, analyzed, and applied effectively to both the society and the economy. The core ontologies that can be derived from the Delphic Maxims are as follows: Self Control, Communication, Respect, God (Religion), Justice, Knowledge, Work, Finance, Family, Honor, Love/Care, and Education.

Each ontology presents a number of concepts that can be developed as distinct knowledge categories with their own interpretation based on their dependencies and usage. The way 
each ontology and ontological structure is applied develops different management approaches under different philosophical thinking.

Example: 'God' imposes 'Love/Care,' which can generate 'knowledge', and through 'respect' and 'work' results in effective 'financial' management. Another way to see the ontologies is that 'knowledge' generates 'self control,' which with 'work' and 'care' results in effective 'financial' management as well.

The first approach is based on the triptych 'God-Love-Knowledge' whereas the second is based on 'Knowledge-Self Control-Work.' They both end in effective financial management and the ensuing benefits, but the approach is different, as the first one is more abstract while the second one is more concrete.

\section{Delphic Maxims Taxonomy}

Starting from the Delphic Maxims ontologies, numerous taxonomies can be generated from each one. The 'Self Control' ontology may generate a number of taxonomies related to self control, based on the maxims that belong to that ontology. Such taxonomies can be the following: Feelings, Acts, Thoughts, Decisions, Advice and more.

Taxonomies may have similar representation structures with ontologies based on the way knowledge is analyzed. Taxonomies can also lead to the development of different management approaches under different philosophical thinking. 'Feelings' for example, activate 'thoughts,' which execute 'acts' based on 'decisions'. Another approach to view this taxonomical representation of knowledge can be that 'decisions' are based on 'feelings' and 'acts', triggered by 'thoughts' (Fig. 3).

In the first case, the maxims drive a proactive management approach where 'thinking' precedes 'acting', while in the second case the maxims drive a reactive approach where 'acting' precedes 'thinking'. Both approaches result in different strategies for a common goal through different philosophy paths. The relationships between the taxonomies can be not only linear but also conditional.

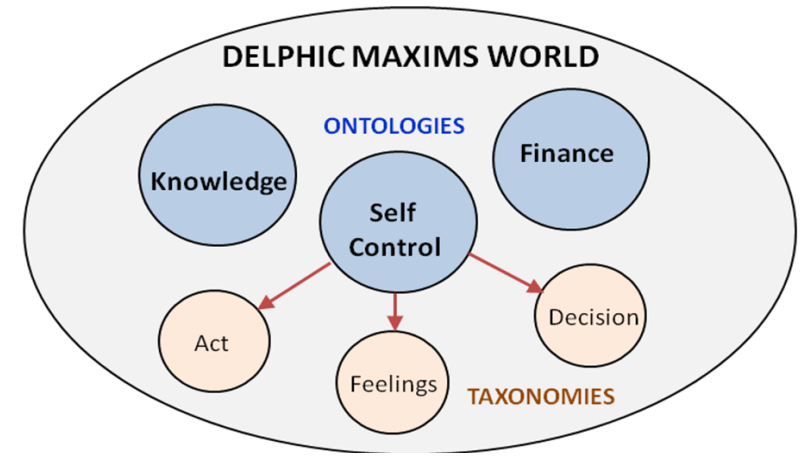

Fig. 3. Delphic Maxim's Taxonomies

\section{Delphic Maxims Classes}

The Delphic Maxims' Taxonomies can generate many classes for each taxonomy. The 'Feelings' taxonomy of the 'Self Control' ontology can include maxims related to the 'control of feelings'. Some of them are: 'Be grateful', 'Control yourself', 'Pursue harmony', and others. Likewise, the 'Decision' taxonomy of the 'Knowledge' ontology can include maxims related to 'decisions based on knowledge. Some of them are: 'Tell when you know', 'Act when you know', 'Venture into danger prudently' and others The classes contain elements with information that can be presented as a process, or as decision/control mechanisms for a wider process. There are a number of maxims, related to 
each other for a specific purpose, revealing knowledge in process-oriented approaches/models. For example, the following classes are constructed with a number of elements from one or more taxonomy or ontology.

Class : Act Wisely : \{'Be/Know Yourself' > [Taxonomy: Feelings, Ontology: Knowledge], 'Foresee the future'> [Taxonomy: Feelings, Ontology: Self Control], 'Perceive what you have heard' $>$ [Taxonomy: Act, Ontology: Knowledge], 'Nothing to excess' > [Taxonomy: Decision, Ontology: Finance], 'Act without repenting'> [Taxonomy: Act, Ontology: Self Control], 'Work for what you can own'> [Taxonomy: Act, Ontology: Finance] \}

The elements of this class create the 'Act Wisely' process. This process states the following: Be/Know Yourself $>$ Foresee the future $>$ Perceive what you have heard $>$ Nothing to excess $>$ Act without repenting $>$ Work for what you can own.

When interpreting this class in structured English, the following applied philosophy is generated: Know yourself first in order to foresee the future correctly, then by utilizing what you hear and with no exaggerations start acting, without looking back, to work on what you can own. The 'Act Wisely' class which derived from elements of three ontologies and three taxonomies, on a unique relationship to a specific process.

\section{A Triadic Classification of Knowledge}

The representation of any type of information and specifically the structured information that generates knowledge, based on the way it is interpreted and analyzed, cannot be classified precisely with a specific classification technique alone [13]. Ontologies for example, indeed provide the high-level representation of knowledge grouped in micro-worlds of information, connected together with various relationships and dependencies [14]. Likewise, taxonomies are derived from ontologies and furthermore classify their information based on more specific categorization schemas, which probably overlap with other taxonomies and ontologies [15].

The discrete line between what type of information can be classified with either ontologies or taxonomies is based on the type of information, the meaning, and the depth of analysis that can be given. Classes, on the other hand, are groups of elements that define the behavior of the information. Classes can be formed with information from one or more taxonomies, with no representation restrictions as classes can be tree-oriented or relationshiporiented. Information that represents knowledge can end up generating classes that can practically turn this knowledge into applied knowledge, composed with elements from different taxonomies and ontologies [16]. In the case of the Delphic Maxims, the classes are philosophical processes applied in small or large procedures, composed of elements from different taxonomies and ontologies (Fig. 4). 


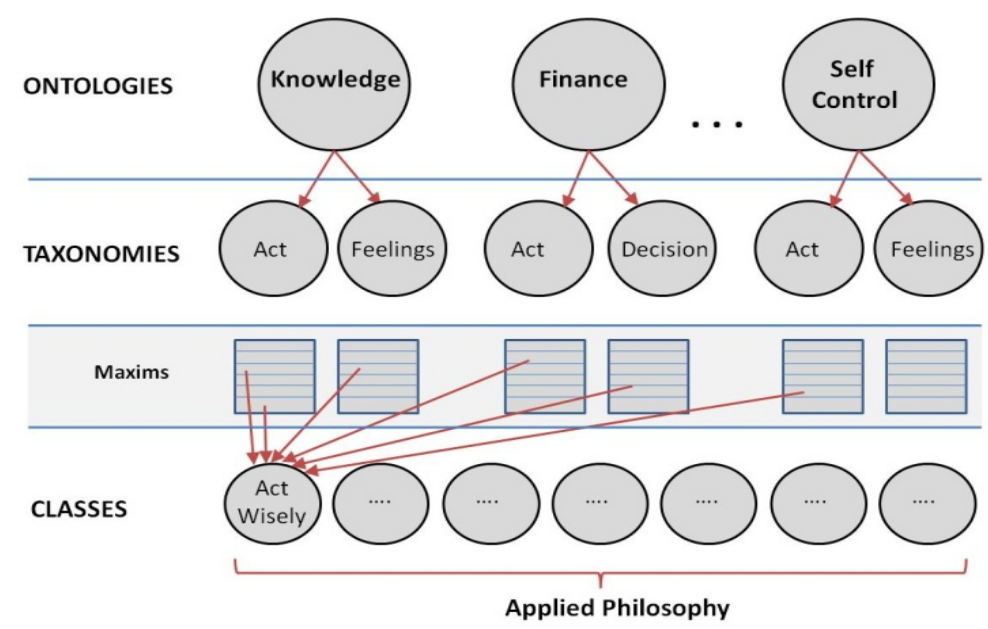

Fig. 4. Triadic classification of knowledge.

This type of information classification could probably considered as one with restrictions on the interpretation of knowledge in the generation of cross-taxonomy and cross-ontology based wisdom. It is that such an unbounded triadic representation of knowledge can be fuzzy and/or hypothetical for knowledge interpretation and classification, but also very rewarding and innovative, if common sense is indeed common.

\section{Business Management Relationships}

Knowledge needs to be interpreted in a way for the creation of value for the science, the economy and the society [17]. Applied knowledge interpretation is a significant issue in knowledge engineering and management [18]. To achieve this, the classification methods and techniques used today need to emphasize on the development of logic driven relationships towards simplifying the knowledge complexity.

The relationships that can derive from the classification of the Delphic Maxims can provide significant applicability in business management, analyzed either in a complex or simple way within the area of a classification technique. Taking for example some Maxims from a specific ontology, a wise process of thinking and acting can be derived that can guide and drive business management acts, logic and thinking.

An example of maxims in the 'Knowledge' ontology that can generate a business management relationship can be the following: \{Know your opportunity, Listen to everyone, Perceive what you have heard, Think as a mortal, Tell when you know $\}$.

Another business management relationship of knowledge can be the 'Self Control' ontology, \{Foresee the future, Use your skill, Act quickly, Act without repenting, Do what you mean to do\}. Likewise, maxims from the 'Finance' ontology can govern business management relationships such as:\{Govern your expenses, Nothing to excess, Work for what you can own, Pursue what is profitable, Benefit yourself $\}$.

The examples given are only a few. Having 147 maxims that encapsulate the entire wisdom of the Hellenic civilization, the knowledge that can be turned into applied philosophy in business management can only be considered as remarkable. In addition to that, if the analysis of the Maxims is extended using a triadic knowledge classification, which enables the creation of business practices with the interconnection of maxims from different taxonomies and ontologies, then the combinations of applied business concepts and processes that can be generated are tremendous. 


\section{The Holistic Concept of Man metaphor}

The analysis of the Delphic Maxims generates practical knowledge that can be characterized as applied philosophy for management and leadership. In the same sense, the Holistic Concept of Man (HCM), a philosophic metaphor described by the Finnish philosopher and psychologist Rauhala [19], integrates the meaning of the Delphic Maxims in defining a mental-oriented knowledge based engine. Pihlanto and Vanharanta have applied the metaphor in the contexts of accounting research and computerized decision support [20], [21]. Further, Rauhala's ideas have been acknowledged in several disciplines, e.g. theoretical information systems and knowledge management [22], [23].

The concept of the HCM metaphor consists of a body, mind, and situation [24]. The three dimensions of the HCM, representing the modes of existence of the actor or decision maker, are called: 1) corporeality, 2) consciousness, and 3) situationality (Fig.5).

The analysis of the Delphic Maxims generates practical knowledge that can be characterised as applied philosophy for management and leadership. In the same sense, the Holistic Concept of Man (HCM) a philosophic metaphor described by Rauhala, a Finnish philosopher and psychologist [19] integrates Delphic Maxim meaning for defining a mental oriented knowledge based engine. Pihlanto and Vanharanta applied the metaphor in contexts of accounting research and computerized decision support [20], [21]. Further, Rauhala's ideas have been acknowledged in several disciplines, e.g. theoretical information systems and knowledge management [22], [23]. The concept of the HCM metaphor consists of a body, a mind and a situation [24]. The three dimensions of the HCM, represent the modes of existence of the actor, the decision maker, are called: 1) corporeality, 2) consciousness, and 3) situationality (Fig, 5).

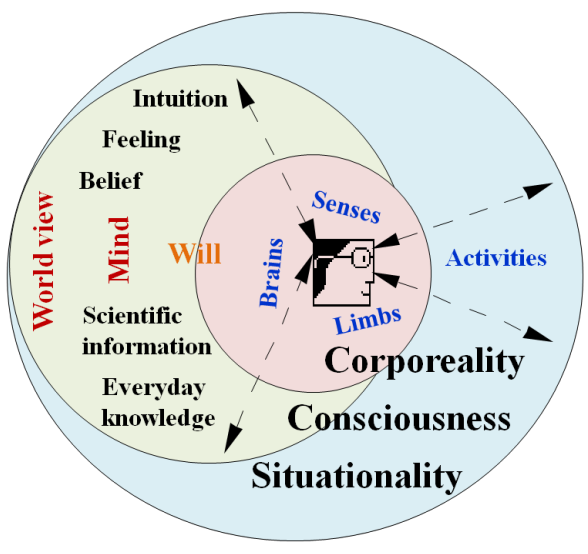

Fig. 5. The Holistic Concept of Man Mental - Physical Contrast

The three modes of existence are intertwined with each other, forming a holistic entity, where the wholeness of interactive modes builds up a "regulative situational circuit" [19], [20]. Corporeality maintains the basic processes of existence emergent expressed as physical activities of the human being. In particular, the human brain and sense organs are important in conveying objects and concepts to the decision maker as meanings in a specific situation. Consciousness stands for experiences and perceptions. It enhances understanding of various phenomena both inside and outside of oneself. Human beings use their outer and inner senses to receive physical signals from the environment in a certain situation, providing the consciousness with meaningful content. Perceiving and understanding the object/concept/relationships make a set of meanings emerge, available for use in the decision making process. Situationality is the decision maker's relevant relations to the outer world, in all its multifaceted pluri-dimensionality. The situational components can be concrete or ideal, the former including nature, buildings, technological equipment, hard- 
ware and software, and the latter human values, norms and human relationships as experienced content [19], [20]. Impulses stimulated by philosophical wisdom and ideals can act as catalysts for knowledge creation and utilization (Fig. 6).

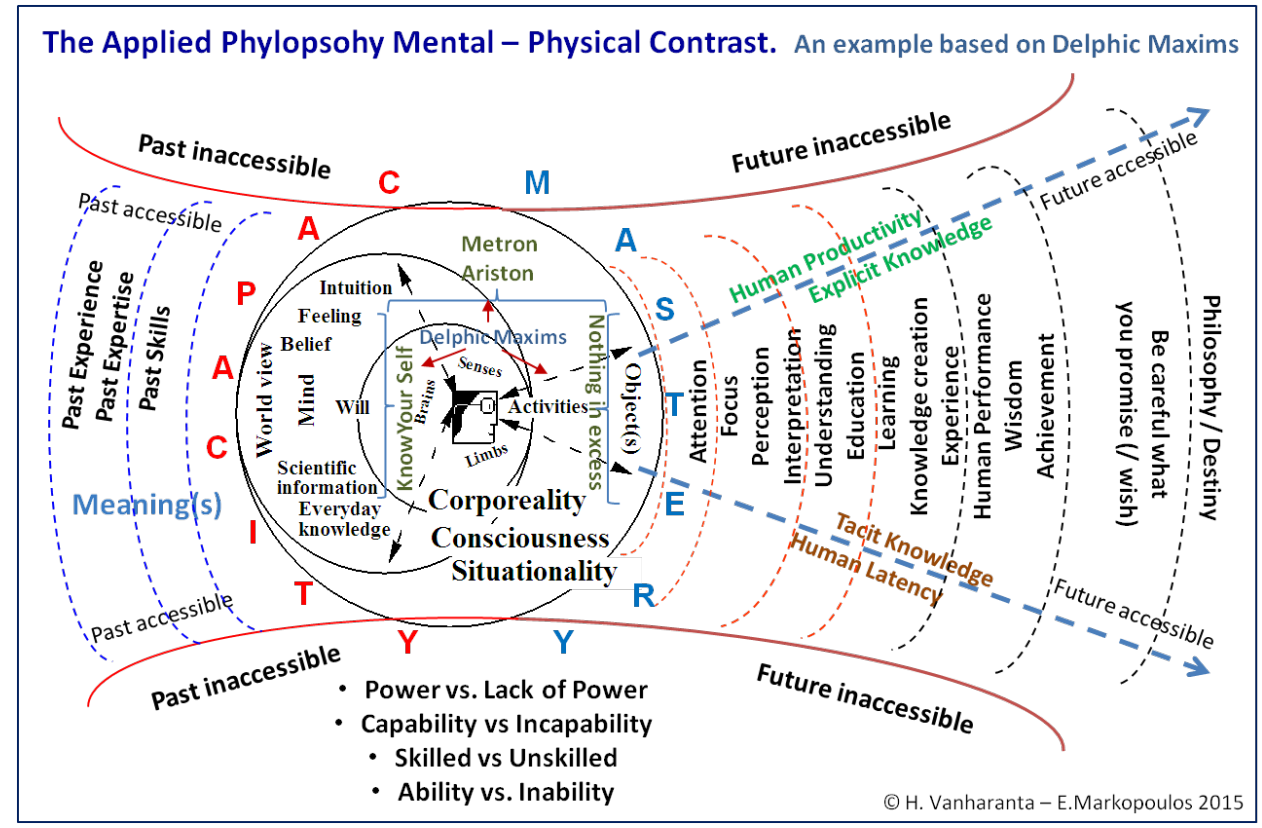

Fig. 6. The Applied Philosophy Mental - Physical Contrast

\section{The Circles of Mind Metaphor}

For someone to understand and apply the Delphic maxims, it is important to understand first him/her self, having 'Gnothiseauton,' the Delphic Maxim for self awareness. The idea of the human being in a specific situation as a totality (Holistic Concept of Man) [19] is not a sufficient metaphor alone in the management and leadership context. The metaphor lacks the new, current research findings on the unconscious part of the human brain and it is also too simple for further use for specific targets; however, it has the important situationality component describing the many connections in human life. Baars [25] has combined psychology with brain science and the old conception of the human mind to create a metaphor based on the workspace of the mind. The totality can be explained through the theater metaphor, where the self as an agent and observer behave as if on the stage. Close to the stage is the unconscious part of the brain (the audience), which is divided into four main areas: the motivational system, automatic systems, interpreting system, and memory system.

The spotlight controller, context, and theater director also belong to the totality in this metaphor. A combination of the Holistic Concept of Man and the theater metaphor of Baars led to a new and very practical metaphor, i.e., the Circles of Mind metaphor [26]. The Circles of Mind metaphor was also designed as a physical entity so the metaphor could be used for many different purposes (Fig 7.).

This has led to the idea of a brain-based system that contains the physical body, following the Cartesian mind-body relationships, i.e., as a thinking substance and an extended substance [27]. Res cogitans "a Thinking Substance" was evident, consisting of the four main parts of the important brain processes affecting the conscious experience on stage. Res extensa, in turn, "an Extended Substance" (body) represents the other dimension of man, the physical dimension of the human being used on the stage. In this article, we bring different management and leadership objects (MOs) to the conscious experience on the stage, 
perceiving and understanding them from different angles and views and giving us the holistic view of their current and also the future coming stage.

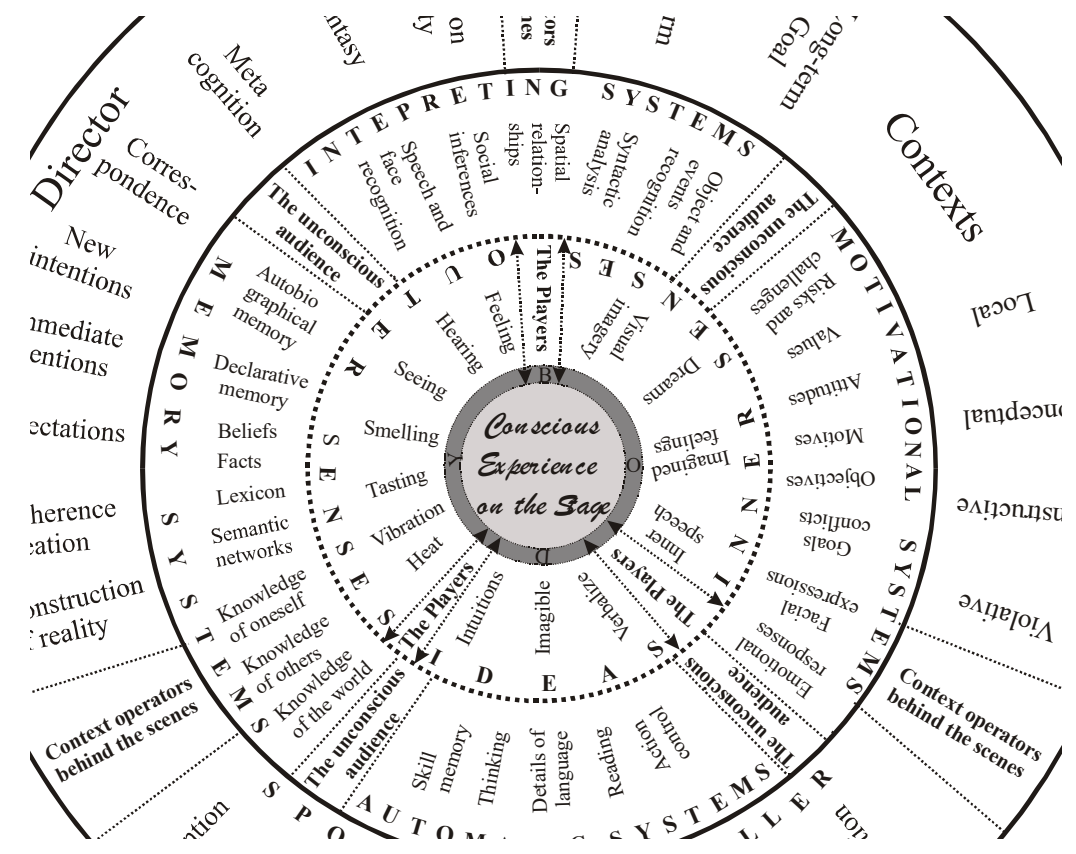

Fig. 7. The Circles of Mind metaphor [26]

Adding many of these personal, individual views and perceptions results in the collective understanding of these management and leadership objects, that is also an important challenge for individuals and organizations.

\section{The Delphic Maxims and Circles of Mind}

The Delphic Maxims give content and commands to the Res cogitans "Thinking Substance" and also to Res extensa "Extended Substance" (body), when these two different philosophical perspectives are put together. The three main maxims of ancient Hellenic wisdom can easily be part of the conscious experience on stage. The most famous of these maxims is 'Know thyself', focusing "Thinking Substance" on the person himself or herself. People must know themselves and this is the most important factor for managers and leaders too - that they really understand themselves better and better. In this thinking, the whole brain capacity should be used, i.e., all the four different sections of the unconscious part of the human brain, but also the conscious part created by the inner and outer senses of human being. Thus the situation or reality is understood and perceived in a holistic way. The Delphic Maxims also give commandments on how people should behave in different situations. "Nothing in excess" gives fundamental recommendations on how people should see both "Res cogitans" as well as "Res extensa" so that the whole entity operates well in a sustainable way. The third main construct "Be careful what you promise/wish" in the Delphi Maxims can be translated in many ways, but in management and leadership this construct gives an overall recommendation in the different situations people find themselves in. 


\section{Socio-Economic Impact}

Applied philosophy has a significant socio-economic impact, which is not easy to measure and evaluate quantitatively. It takes much more than business sense to identify the tremendous benefits that philosophy can offer the society and the economy, once effectively transformed into business management processes and practices. The great civilizations have contributed the most fundamental elements on which society can build today's and tomorrow's achievements. Anything made in the past had a reason, a cause, a practicality, a justification and a return not only to the ones developing but also to the society and the economy as a whole. Such thinking is called Applied Philosophy.

Humanity managed to evolve due to such philosophy-driven thinking for the progress and prosperity of the community not the individual, for common drivers and ideals. Shared value was placed highly on the expected outcomes of everything attempted to be designed and developed. Therefore, trying to understand the thinking of Hellenic civilization and others as well is very important in the development of sustainable business models that can stand the test of time. Advancements in the development of classification techniques, processes, and models not only utilize the dowry left to us by our ancestors, but also provide a deeper understanding on integrating this knowledge in today's society and economy.

Utilizing such a magnificent wealth of knowledge heritage can only be achieved if the mindset of those analyzing it, turning it into business practices and applying it as well, is not far from the mindset of their ancestors, at it is impossible to see what those people had seen. Without such a mindset this knowledge, that could resolve so many problems of the modern economy and society, will not be utilized effectively, despite the current advancements in technology and communications. As long as today's managers value business more than society, not seeing that society is the economy, no classification of any such knowledge will be achieved effectively and rewardingly for all.

\section{Areas of Further Research}

Efforts on the classification of the existing knowledge in humanity through techniques, methods, and models that can turn this knowledge into applicable contributions to the modern economy and business management need to be continued. The Delphic Maxims are one set of knowledge that can generate significant business management values, but it is not the only one in the Hellenic philosophical contribution to the world.

Further research will be done on specific Hellenic philosophers, whose life and work can be related to vertical business management needs and practices. The knowledge of Socrates, for example, can contribute enormously to understanding the requirements elicitation process which greatly inconveniences all projects in all sectors today. Insufficient requirements cause tremendous financial and operational costs for organizations not defining and handling them properly in the tendering, acquisition, and development stages of a project.

Plato's knowledge can be classified for developing change management and reengineering practices. Pericles' knowledge is highly suitable for project, program and product management, Aristotle's for organizational strategy, Thucydides for extroversion and internalization, Isocrates for teamwork management, Heraclitus for human resources management, Homer for design and production management, Herodotus for process, tactic and strategic management, Pythagoras for innovation management, Democritus for engineering management, and Solon for organizational leadership. In a similar way, knowledge from other significant civilizations, such as the Egyptian, Chinese, or Roman, can be categorized through the triadic knowledge representation approach (Ontologies, Taxonomies, Classes), and analyzed using the Circles of Mind, the Holistic Concept of the Man, and other knowledge creation models for added and shared value (Fig 8). 


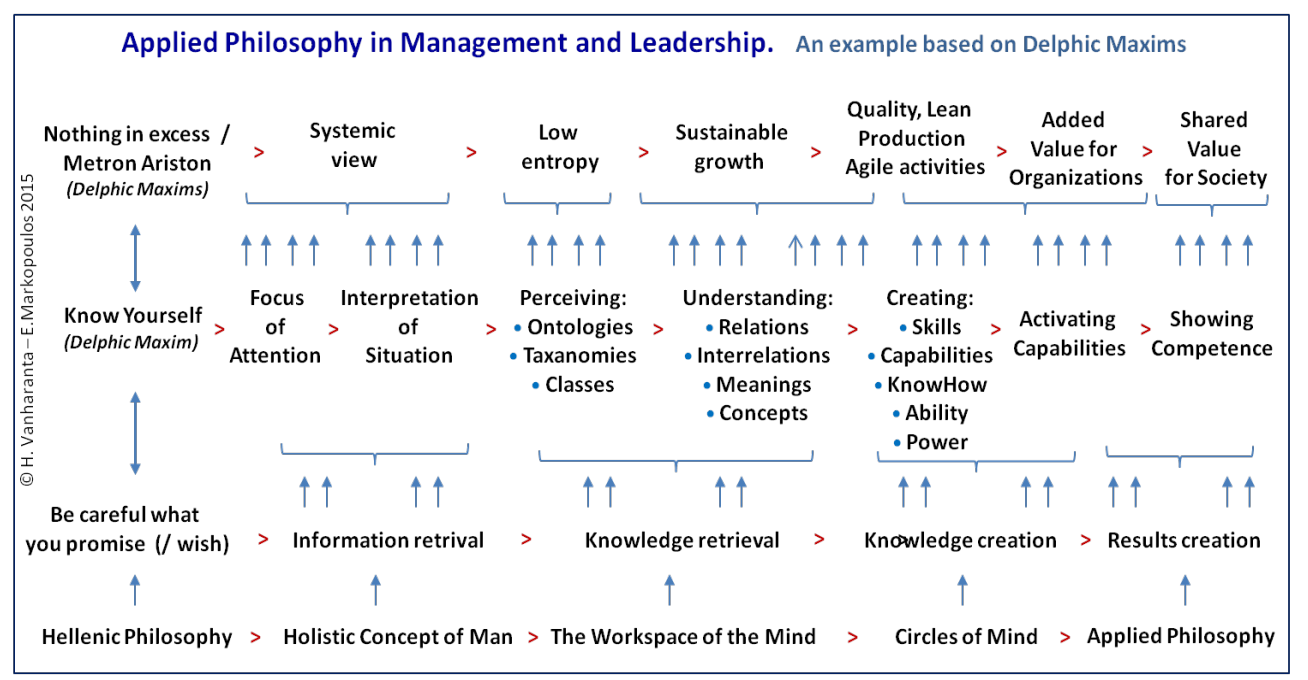

Fig. 8. Applied philosophy based knowledge management creation and utilization.

The research will also extend towards supporting the 'Applied Philosophy' concept by optimizing the classification process, the creation of new classification terminology, notation and diagramming techniques to capture concepts with relative interpretation and applicability to the business, the society and the economy.

\section{Conclusions}

A black hole in knowledge management is the definition of knowledge itself. What is knowledge and what is not is a very fuzzy concept. Knowledge can be generated by analyzing any information properly, giving results that can be applied either in theory, for further research or in practice. The difference between knowledge and information is that information is unprocessed knowledge. Today people try to generate knowledge through a number of complex approaches and scientific disciplines without any certainty on the quality of the results achieved. It seems that any scientific approach towards creating knowledge can contribute to the evolution and progression of the economy, society and the humanity, but this is not actually true. Knowledge cannot be produced in artificial environments. Knowledge is a living entity, growing organically in many forms and sources, and free to those able to seek it.

Instead of investing in knowledge engineering efforts using artificial intelligence technologies, neuro-management [28], cognitive sciences [29], and in all the state-of-the-art progress that people have significantly achieved over the years, it might be wiser to admit that knowledge, in a probably much more valuable form, can be found in the roots of past civilizations. With the proper classification techniques, methods, and models, the knowledge that can be extracted by analyzing history may surpass in value and return to the society and the economy the knowledge that is attempted to be generated through today's efforts to read people's minds [30]. Applied philosophy is not rocket science but simply common sense, but common sense doesn't seem to be common at all.

The 147 laconic statements composing the Delphic Maxims can redefine the business management and operations strategies and practices once properly classified and studied with common sense. The wisdom of the Delphic Maxims is not the only one in the world. Many nations contributed, more or less, to evolution of the human knowledge and wisdom, therefore studying the past, and not only the present, can lead us to effective reactive solutions on problems we face, or proactive by avoiding those that can come up. 


\section{The Delphic Maxims}

The core Ancient Hellenic wisdom, in the 147 Delphic Maxims are listed in table 1.

Table 1. The Delphic Maxims.

\begin{tabular}{|c|c|c|}
\hline & Delphic Maxims & \\
\hline - Follow God & - Teach a youngster & - Act without repenting \\
\hline -Obey the law & - Acquire wealth justly & - Repent of sins \\
\hline - Be overcome by justice & - Do not trust wealth & - Control the eye \\
\hline -Love friendship & -Cling to discipline & -Control anger \\
\hline - Perceive what you have heard & $\begin{array}{l}\text { - Finish the race without } \\
\text { shrinking back }\end{array}$ & - Be happy with what you have \\
\hline -Know Yourself & -Long for wisdom & -Honor providence \\
\hline - Intend to get married & -Praise the good & - Do not use an oath \\
\hline - Know your opportunity & -Find fault with no one & - Do a favor for a friend \\
\hline - Think as a mortal & - Praise virtue & - Nothing to excess \\
\hline $\begin{array}{l}\text {-If you are a stranger act like } \\
\text { one }\end{array}$ & $\begin{array}{l}\text { - Be accommodating in every- } \\
\text { thing }\end{array}$ & $\begin{array}{l}\text { - Give back what you have } \\
\text { received }\end{array}$ \\
\hline - Venture into danger prudently & -Shun what belongs to others & - Do not be discontented by life \\
\hline - Know what you have learned & - Watch out for your enemies & - Work for what you can own \\
\hline - Keep yourself from insolence & -Exercise nobility of character & -Observe what you have heard \\
\hline - Help your friends & -Shun evil & -Control anger \\
\hline - Control yourself & - Be impartial & -Exercise prudence \\
\hline - Pursue honor & - Guard what is yours & -Honor providence \\
\hline -Exercise prudence & -Use time sparingly & - Do \\
\hline -Despise insolence & -Listen to everything & - Do a favor for a friend \\
\hline -Foresee the future & - Be (religiously) silent & - Nothing to excess \\
\hline - Beget from noble routes & -Consult the wise & - Use time sparingly \\
\hline - Act when you know & - Test the character & -Foresee the future \\
\hline -Live together meekly & -Love whom you rear & -Despise insolence \\
\hline - Govern your expenses & -Down-look no one & - Use \\
\hline - Accuse one who & spect for suppliants & - Associate with your peers \\
\hline - Rever a sense of shame & - Do what you mean to do & -Educate your sons \\
\hline - Give a timely counsel & -Honor a benefaction & - Give what you have \\
\hline - Deal kindly with everyone & -Make promises to no one & -Fear deceit \\
\hline - Do not curse your sons & -Shun murder & -Speak well of everyone \\
\hline - Act quickly & -Pray for things possible & eeker of wisdom \\
\hline - Give a timely response & - Be jealous of no one & -Choose what is divine \\
\hline -Struggle with glory & guard & -Fulf \\
\hline - Do not wrong th & $-\operatorname{Pra}$ & -Pra \\
\hline - Be well off as a mortal & - Be fond of fortune & -Despise a slanderer \\
\hline - Do not trust fortune & - Guard friendship & -Rule your wife \\
\hline - Benefit yourself & - Gratify without harming & - Be kind to friends \\
\hline - Be courteous & -Despise strife & -Practice what is just \\
\hline - Judge incorrul & disgrace & $-\mathrm{Be}$ \\
\hline ssions justly & tongue & $-\mathrm{Pu}$ \\
\hline religious) silence & for suppliants & ly the top secret \\
\hline -Knov & -Make just judgements & -Fea \\
\hline - Master wedding-feasts & - Use what you have & -Pursue what is profitable \\
\hline - Recognize fortune & - Tell when you know & - Accept due measure \\
\hline - Flee a pledge & - Worship the Gods & - Do away with enmities \\
\hline -Speak & ut sorrow & $-A$ \\
\hline - Respect your parents & -Desp & ir country \\
\hline abandon honor & oracles & -Griev \\
\hline - Do not tire of learning & - Do not stop to be thrifty & - Respect yourself \\
\hline -Honor good men & -Respect the elder & - Honor the hearth \\
\hline -Flee enmity & -Do not boast in might & - Crown your ancestors \\
\hline - Do not depend on strength & - Do not begin to be insolent & - As a child be well-behaved \\
\hline
\end{tabular}



- On reaching the end be with- - Do not oppose someone - As a youth be self-disciplined out sorrow absent
- Do not make fun of the dead -Share the load of the unfor- - As of middle-age be just tunate

- As an old man be sensible

\section{References}

1. Markopoulos E., Vanharanta H.: Democratic Culture Paradigm for Organizational Management and Leadership Strategies - The Company Democracy Model. Proceedings of the 5th International Conference on Applied Human Factors and Ergonomics AHFE 2014, Kraków, Poland 19-23 July 2014 (2014)

2. Bowden H.: Classical Athens and the Delphic Oracle: Divination and Democracy, Cambridge University Press page.82, 5 May 2005

3. Markopoulos, E.: The Kapodistrian Principles for Freedom through Knowledge and Education. Ioanis Kapodistrias Conference. 30 October 2013, Athens, Greece (2013)

4. Markopoulos E., Vanharanta H.: Company Democracy Model for Development of Shared Value, 6th International Conference on Applied Human Factors and Ergonomics (AHFE), 26-30 July 2015, Las Vegas, USA

5. Parke H., Wormell D.: The Delphic Oracle, Basil Blackwell, vol. 1, p. 389, (1956),

6. Oikonomides, A.N. : Records of "The Commandments of the Seven Wise Men" in the 3rd century B.C. The Classical Bulletin, Vol. 63(3), 1987, pp 67-76. (1987)

7. Nonaka I., Takeuchi H.: The Knowledge-Creating Company: How Japanese Companies Create the Dynamics of Innovation'. New York, Oxford University Press. (1995)

8. Bonacin R.,et al.: From Ontology chart s to Class diagrams: semantic analysis aiding systems design. In: Proceedings of the 6th International Conference on Enterprise Information Systems, Porto, (2004).

9. Richardson L.: Taxonomy of the Programmable Web, Nov 05 2006, http://www.crummy.com/2006/11/05/2 (2006)

10. Oberle, D., Guarino, N., Staab, S.: What is an ontology?. In: "Handbook on Ontologies". Springer, 2nd edition, 2009.

11. Tulu B, Chatterjee S, Maheshwari M: Telemedicine taxonomy: a classification tool, Telemed J E Health. 2007 Jun;13(3): pp.349-58.

12.Ambysoft Inc: UML 2 Class Diagrams: An Agile Introduction, www.agilemodeling.com /artifacts/classDiagram.htm Sited: Aug.20.2015

13. Brachman, R.: A Structural Paradigm for Representing Knowledge. Bolt, Beranek, and Neumann Technical Report (3605). (1978).

14. Mizoguchi, R.: Tutorial on ontological engineering: part 3: Advanced course of ontological engineering. In: New Generation Computing. Ohmsha \& Springer-Verlag, 22(2): 198-220. (2004)

15. Jackson, J.: Taxonomy's not just design, it's an art. Government Computer News (Washington, D.C.). September 2, 2004

16. Ades, Y, Farouk Ben-Oman, Iman Poernomo, George Tsaramirsis.: Mapping Ontology Charts to Class Diagrams, ICOS (2007).

17. Guibert B., Laganier J., Volle M.: An Essay on Industrial Classifications, Économie et statistique 20, February 1971

18. Feigenbaum, E., McCorduk, P.:. The Fifth Generation (1st ed.). Reading, MA: AddisonWesley.1983

19. Rauhala L. Ihmiskäsitys I.: The Conception of Human Being in Helping People. Helsinki: Gaudeamus, 1986

20. Vanharanta H, Pihlanto P, Chang A-M.: Strategic Decision support systems in a hyperknowledge environment and the holistic concept of the decision maker. In Walden P, Brännback M, Back B, Vanharanta H, editors. The Art and Science of Decision-Making. Turku: Åbo Akademi University Press; 1996. p. 243-258 (1996)

21. Vanharanta H, Salminen T.: Holistic interaction between the computer and the active Human being. In: Jacko J, editor. Human-computer interaction, Part I, HCII 2007. Heidelberg: Springer; 2007.p. 252-261. (LNCS, vol. 4550), (2007) 
22. Isomäki H.K.: The prevailing conceptions of the human being in information systems development: systems designers' reflections [Online]. Electronic dissertation. Acta Universitatis Tamperensis 188. 2002.

23. Ojala M.: Toimintakyky ja toimintaedellytykset - käsitteistä tiedonhallintaan osa 2, Functioning and the Prerequisites for Functioning - from Concepts to Managing Knowledge, Part 2. In: Lecture Notes in Re-habilitation Training, the Open University of Oulu. Oulu, Finland; 2004.

24. Hakula J.: The Purola model and the Holistic Concept of Man metaphor as bases for the networked view of decision making in eHealth and eWelfare, Finnish Journal of eHealth and Welfare, FinJeHeW 2009;1(2), pages 107-117 (2009)

25. Baars, B., J.: In the Theater of Consciousness The Workplace of the Mind, Oxford University Press, 1997, p.193 (1997)

26. Vanharanta, H.: Circles of mind. Identity and diversity in organizations - building bridges in Europe Programme XIth European congress on work and organizational psychology 14-17 May 2003, Lisboa, Portugal. (2003)

27. Maslin, K., T.,: An Introduction to the Philosophy of Mind. (p. 313). Malden: Blackwell Publishers Inc. (2001)

28. Satpathy J.: Issues in Neuro - Management Decision Making, Opinion: International Journal of Business Management, Vol. 2, No. 2, December 2012

29. Mischel T.: Cognitive Development and Epistemology. Academic Press, 2013

30. Piccinini G.: The First Computational Theory of Mind and Brain: A Close Look at Mcculloch and Pitts's 'Logical Calculus of Ideas Immanent in Nervous Activity, Synthese 141(2) (August 2004): 175-215. (2004)

\section{About the Authors}

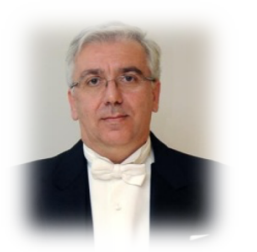

Prof. Dr. Evangelos Markopoulos is a leading expert, entrepreneur, scientist and scholar in the field of technology and particularly in knowledge management, project management and management innovation with applications in technocratic business development, techno-economic and technocratic business management of projects and investments at national and international level. He holds a $\mathrm{BA}$ and an MSc degree in computer science and a Ph.D. in Information Technology Projects and Investments Management. epm@empross.com

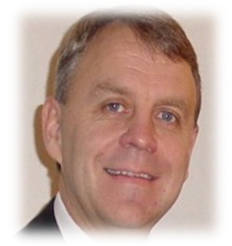

Prof. Dr. Hannu Vanharanta, began his professional career in 1973 as Technical Assistant at the Turku office of the Finnish Ministry of Trade and Industry. Since 1998 he has been professor in Industrial Management and Engineering in Tampere University of Technology at Pori. The research interests are: Human Resource Management, Knowledge Management, Strategic Management, Financial Analysis, and Decision Support Systems. He has had special interest in knowledge discovery and data mining. hannu@vanharanta.fi 